\title{
The First Data on the Oxygen, Carbon, and Sulfur Isotope Composition of the Chelyabinsk Meteorite
}

\author{
Academician A. I. Khanchuk ${ }^{a}$, V. I. Grokhovskii ${ }^{b}$, A. V. Ignat'ev ${ }^{a}$, \\ T. A. Velivetskaya ${ }^{a}$, and S. I. Kiyashko ${ }^{a}$ \\ Received May 8, 2013
}

DOI: $10.1134 / \mathrm{S} 1028334 X 1309016 \mathrm{X}$

Meteorites are the main source of extraterrestrial material for investigation of regularities of the formation and evolution of solar system matter. The genetic connection of a concrete meteorite to an assumed parental body is based on meteorite classification, which is mostly supported by study of their mineralogical and petrographic characteristics, as well as investigation of the bulk chemical composition [1]. In 1973 R. Clayton et al. [2] discovered an anomalous concentration of the ${ }^{17} \mathrm{O}$ isotope in meteorites in comparison with terrestrial rocks. The main differences between terrestrial and extraterrestrial material are controlled by primary isotope heterogeneities in the early solar system. Further investigations of the relative concentration of stable isotopes ${ }^{16} \mathrm{O},{ }^{17} \mathrm{O}$, and ${ }^{18} \mathrm{O}$ provided the oxygen isotope classification of meteorites and planets and allowed characterization of two important processes of the evolution of the solar system: chemical fractionation and mixing of the components of protoplanetary materials with various isotope compositions [3]. In recent years special attention has been paid to investigation of variations in the stable isotopes in meteorites during genetic identification of meteorites and study of the evolution of the matter of the solar system. For this purpose we investigated the oxygen, sulfur, and carbon isotope compositions of a fragment of Chelyabinsk meteorite.

Chelyabinsk meteorite rain was registered on February 15, 2013, in Chelyabinsk oblast (Russia). The meteorite was related to the LL group of ordinary chondrites, petrological type 5, shock fraction S4, and weathering degree W0 [4]. An individual fragment of the Chelyabinsk meteorite with a weight of $7 \mathrm{~g}$ was used for preparation of bulk samples for the oxygen and carbon isotope analysis. The bulk sample with a total weight of $800 \mathrm{mg}$ was collected from the light part

\footnotetext{
${ }^{a}$ Far East Geological Institute, Far East Branch, Russian Academy of Sciences, Vladivostok, Russia

${ }^{b}$ Physical-Technological Institute, El'tsyn Ural Federal

University, Yekaterinburg, Russia

e-mail:fegi@online.marine.su
}

of the meteorite and ground in an agate mortar. None of the chemical methods of treating was applied, since the weathering degree of the Chelyabinsk meteorite was zero (W0). A section with a thickness of $3 \mathrm{~mm}$ was cut from the meteorite fragment and polished for local analysis of the sulfur isotope composition.

The oxygen isotope composition of the meteorite was performed by the laser method of fluoration. Meteorite samples with a weight of $0.9-1.5 \mathrm{mg}$ were loaded into the reactor together with international standards (quartz NBS-28 and garnet UWG-2). Oxygen was extracted by sample heating by an infrared laser (MIR-10-30, New Wave Research) in atmosphere of $\mathrm{BrF}_{5}$ vapor. In contrast to traditional laser methods [5, 6], we carried out additional oxygen cleaning on a capillary chromatographic column MOLSIV (length $25 \mathrm{~m}$, inner diameter $0.32 \mathrm{~mm}$, working temperature $60^{\circ} \mathrm{C}$ ) in order to increase the reliability of the results. After separation of gases on a chromatographic column, the oxygen isotope composition was analyzed on a MAT 253 mass spectrometer in continuous helium flow. $\delta^{18} \mathrm{O}$ and $\delta^{17} \mathrm{O}$ were measured in relation to the laboratory standard $\mathrm{O}_{2}$ calibrated against the international standard NBS-28 and standard UWG-2 [7]. The results of $\delta^{18} \mathrm{O}$ and $\delta^{17} \mathrm{O}$ measurements are given in the generally accepted form: $\delta=\left(\mathrm{R}_{\text {sample }} / \mathrm{R}_{\text {standard }}-1\right) \times 1000(\%)$, where $\mathrm{R}_{\text {sample }}$ and $\mathrm{R}_{\text {standard }}$ are the ratios ${ }^{18} \mathrm{O} /{ }^{16} \mathrm{O}$ and ${ }^{17} \mathrm{O} /{ }^{16} \mathrm{O}$ in the sample and standard, respectively. $\delta$ values are expressed in relation to the international standard VSMOW. The reproducibility of $\delta^{18} \mathrm{O}$ and $\delta^{17} \mathrm{O}$ by standards $(1 \sigma)$ was 0.07 and $0.06 \%$ for $\delta^{18} \mathrm{O}$ and $\delta^{17} \mathrm{O}$, respectively.

Carbon isotope analysis was performed by the traditional methodology on an element analyzer FlashEA-1112. Carbon isotope analysis was performed using aliquots of the ground material with a weight from 4.86 to $20.48 \mathrm{mg}$. $\delta^{13} \mathrm{C}$ was analyzed on a MAT 253 mass spectrometer against the laboratory standard $\mathrm{CO}_{2}$ calibrated against international standards CH-6 and NBS-22. The results of $\delta^{13} \mathrm{C}$ measurements are given in the generally accepted form in 
Table 1. The oxygen isotope composition in bulk samples of the Chelyabinsk meteorite, \%o

\begin{tabular}{c|c|c|c}
\hline & $\delta^{17} \mathrm{O}$ & $\delta^{18} \mathrm{O}$ & $\Delta^{17} \mathrm{O}$ \\
\hline \multirow{5}{*}{} & 3.78 & 4.97 & 1.19 \\
& 3.81 & 4.94 & 1.24 \\
& 3.83 & 4.95 & 1.25 \\
& 3.72 & 4.87 & 1.19 \\
& 3.87 & 4.95 & 1.30 \\
& 3.75 & 4.87 & 1.22 \\
& 3.76 & 4.79 & 1.26 \\
& 3.88 & 5.08 & 1.23 \\
& 3.80 & 5.05 & 1.17 \\
Average & 3.76 & 4.86 & 1.23 \\
& 3.95 & 5.07 & 1.31 \\
& 0.07 & 4.95 & 1.24 \\
\hline
\end{tabular}

Table 2. Carbon isotope composition and concentration of carbon (wt \%) in the Chelyabinsk meteorite

\begin{tabular}{c|r|r|r}
\hline & Weight, mg & $\delta^{13} \mathrm{C}, \%$ o & C, wt \% \\
\cline { 2 - 4 } & 4.86 & -23.1 & 0.09 \\
17.14 & -23.4 & 0.13 \\
20.48 & -23.4 & 0.13 \\
& 13.19 & -23.7 & 0.12 \\
& 8.99 & -23.1 & 0.13 \\
Average & 18.30 & -23.5 & 0.12 \\
$1 \sigma$ & & -23.4 & 0.10 \\
& & 0.2 & 0.02 \\
\hline
\end{tabular}

relation to the international standard VPDB. Reproducibility of $\delta^{13} \mathrm{C}$ for standard samples $(1 \sigma)$ is $0.05 \%$.

The local analysis of sulfur isotopes was performed by the method of laser ablation by original methodology worked out at the Far East Geological Institute, Far East Branch, Russian Academy of Sciences. This methodology allows us to investigate $\delta^{34} \mathrm{~S}$ variations in sulfides with a spatial resolution of $50-100 \mu \mathrm{m}$. The polished section of the meteorite and samples of international standards IAEA-S-1, IAEA-S-2, and IAEAS-3 were loaded into a camera blown by helium. An Integra-C infrared laser of ultrashort impulses was applied for ablation. The diameter of the crater from the laser beam on the troilite surface was $80-100 \mu \mathrm{m}$. Particles of matter thrown out from the crater were transported to an oxidizing reactor in helium flow $(100 \mathrm{~mL} / \mathrm{min})$. Oxidized sulfur was accumulated in
Table 3. Sulfur isotope composition of individual troilite inclusions in the Chelyabinsk meteorite

\begin{tabular}{|c|c|c|c|c|}
\hline $\begin{array}{l}\text { No. of } \\
\text { troilite } \\
\text { inclusion }\end{array}$ & $n$ & $\delta^{34} \mathrm{~S}, \%$ & $\begin{array}{c}\text { No. of } \\
\text { troilite } \\
\text { inclusion }\end{array}$ & $\delta^{34} \mathrm{~S}, \%$ \\
\hline \multirow[t]{7}{*}{1} & 1 & 0.20 & 5 & 0.34 \\
\hline & 2 & 0.16 & 6 & 0.35 \\
\hline & 3 & 0.24 & 7 & 0.22 \\
\hline & 4 & 0.30 & 8 & 0.38 \\
\hline & 5 & 0.18 & 9 & 0.41 \\
\hline & \multirow[t]{2}{*}{6} & 0.23 & 10 & 0.35 \\
\hline & & $\begin{array}{ll}\text { Average } & 0.22 \\
1 \sigma & 0.05\end{array}$ & 11 & 0.27 \\
\hline \multirow[t]{4}{*}{2} & 1 & 0.53 & 12 & 0.07 \\
\hline & 2 & 0.49 & 13 & 0.32 \\
\hline & 3 & 0.46 & 14 & 0.17 \\
\hline & & $\begin{array}{ll}\text { Average } & 0.49 \\
1 \sigma & 0.03\end{array}$ & 15 & 0.19 \\
\hline \multirow[t]{4}{*}{3} & 1 & 0.36 & 16 & 0.56 \\
\hline & 2 & 0.27 & 17 & 0.25 \\
\hline & 3 & 0.22 & & \\
\hline & & $\begin{array}{ll}\text { Average } & 0.28 \\
1 \sigma & 0.07\end{array}$ & & \\
\hline \multirow[t]{5}{*}{4} & 1 & 0.39 & & \\
\hline & 2 & 0.40 & & \\
\hline & 3 & 0.37 & & \\
\hline & 4 & 0.43 & & \\
\hline & & $\begin{array}{ll}\text { Average } & 0.40 \\
1 \sigma & 0.03\end{array}$ & & \\
\hline \multicolumn{4}{|c|}{ Average by all troilite inclusions } & $0.31 \%$ \\
\hline
\end{tabular}

Note: Local analyses of $\delta^{34} \mathrm{~S}$ for individual troilite inclusions nos. $1-4$ were performed in several points ( $n$ are the points); inclusions nos. 5-17 were analyzed without repetitions.

the capillary trap cooled by liquid nitrogen. After cryogenic cleaning, $\mathrm{SO}_{2}$ was transported by helium flow to the ion source of a MAT 253 mass spectrometer. The ${ }^{34} \mathrm{~S} /{ }^{32} \mathrm{~S}$ ratios in troilite inclusions were measured in relation to the international standard IAEA-S-1, and the obtained values of $\delta^{34} \mathrm{~S}$ were expressed in relation to VCDT. The reproducibility of $\delta^{34} \mathrm{~S}$ by standards $(1 \sigma)$ was $0.10 \%$.

The results of measurements of the relationships between stable oxygen isotopes in 11 bulk samples of the Chelyabinsk meteorite are given in Table 1. Calculation of $\Delta^{17} \mathrm{O}$ values was carried out by the methodology suggested by $\mathrm{R}$. Clayton, in which $\Delta^{17} \mathrm{O}$ is determined as the difference between $\delta^{17} \mathrm{O}$ and $\delta^{18} \mathrm{O} \times 0.52$ [1].

The average values of $\delta^{17} \mathrm{O}, \delta^{18} \mathrm{O}$, and $\Delta^{17} \mathrm{O}$ for the Chelyabinsk meteorite are $3.81(1 \sigma=0.07), 4.95$ $(1 \sigma=0.09)$, and $1.24 \% \circ(1 \sigma=0.04)$, respectively. The 


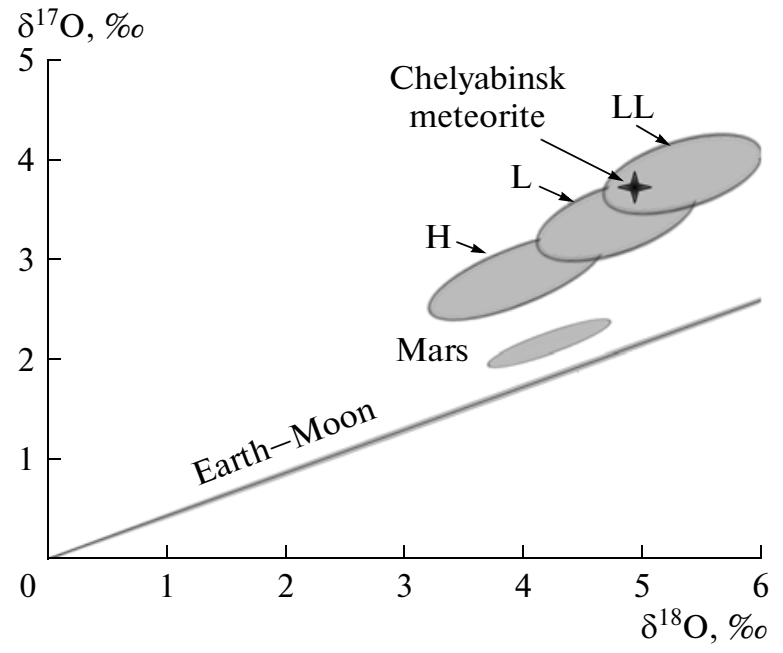

Fig. 1. Relationship between $\delta^{17} \mathrm{O}$ and $\delta^{18} \mathrm{O}$ in $\mathrm{H}-\mathrm{L}-\mathrm{LL}$ meteorites, Martian meteorites, and the line of massdependent fractionation of oxygen isotopes in terrestrial and lunar rocks. The asterisk indicates the oxygen isotope composition of the Chelyabinsk meteorite. Data from [3, 8] are shown.

relationship between these values is illustrated on the graph (Fig. 1). The isotope composition of Chelyabinsk meteorite differs from the trend of mass-dependent fractionation of terrestrial samples by $\Delta^{17} \mathrm{O}=$ $1.24 \%$. The values $\delta^{17} \mathrm{O}$ and $\delta^{18} \mathrm{O}$ plot in the area typical of meteorites of the LL group, according to the Clayton isotope classification [3]. Thus, the Chelyabinsk meteorite belongs to the LL group, which was established by the isotope data and is consistent with the results of classification of this meteorite by the petrological, mineralogical, and chemical analyses [4].

The relationships between carbon stable isotopes and the carbon concentration in the Chelyabinsk meteorite are given in Table 2. The average value of the carbon isotope composition $\delta^{13} \mathrm{C}$ in six bulk samples of the Chelyabinsk meteorite is $-23.4 \%$ in relation to VPDB. The reproducibility of the $\delta^{13} \mathrm{C}$ measurement in six bulk samples with a weight from 4.86 to $20.48 \mathrm{mg}$ is $0.2 \%$ o $(1 \sigma)$.

The average carbon concentration in the Chelyabinsk meteorite is $0.1 \mathrm{wt} \%$ determined with an accuracy of $0.02 \%(1 \sigma)$. The obtained average values of $\delta^{13} \mathrm{C}-23.4 \%$ and the concentration of carbon in the Chelyabinsk meteorite plot in the area typical of ordinary chondrites of the $\mathrm{H}-\mathrm{L}-\mathrm{LL}$ classes with registered falls (Fig. 2). The found meteorites are usually characterized by higher $\delta^{13} \mathrm{C}$ values, which is most likely explained by their pollution or isotope exchange with terrestrial carbon [9]. In accordance with the characteristics of the Chelyabinsk meteorite, the degree of its weathering is zero [4], and we assume that

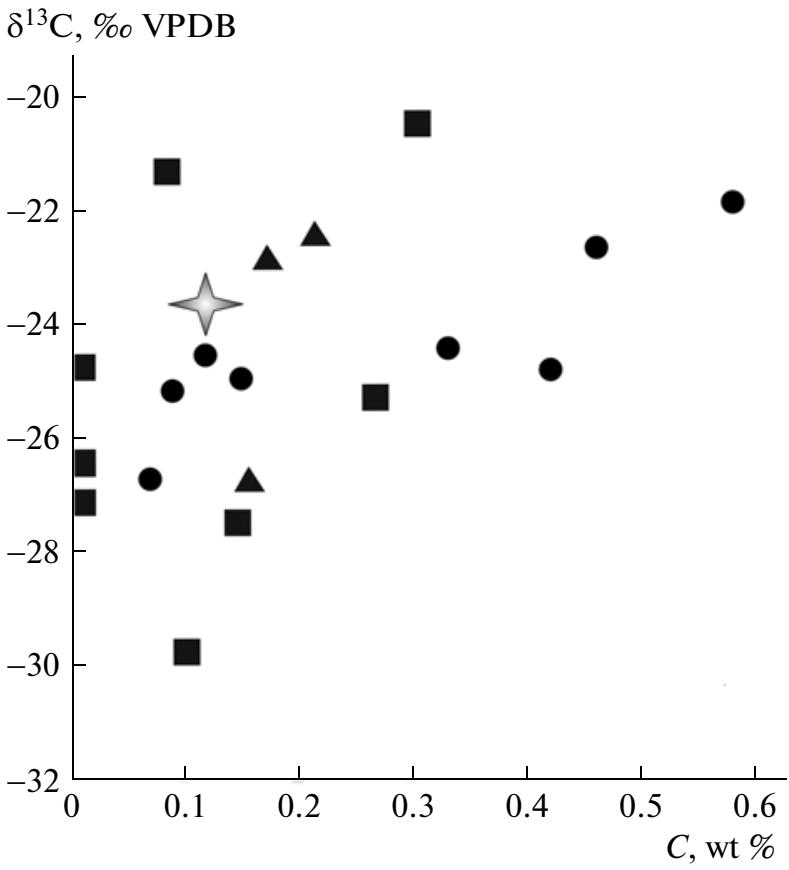

Fig. 2. $\delta^{13} \mathrm{C}$ and carbon concentration (wt \%) in $\mathrm{H}-\mathrm{L}-\mathrm{LL}$ meteorites. The asterisk indicates the carbon isotope composition of the Chelyabinsk meteorite. Meteorites: $\mathrm{H}$ (squares), L (triangles), LL (points); data from [9].

the Chelyabinsk meteorite is not polluted with terrestrial carbon and its isotope composition $(-23.4 \%$ ) corresponds to the primary value of $\delta^{13} \mathrm{C}$.

Troilite inclusions with a size exceeding $100 \mu \mathrm{m}$ were selected in the Chelyabinsk meteorite for local analysis of $\delta^{34} \mathrm{~S}$. Seventen troilite inclusions following requirements of the local analysis of sulfur isotope composition were selected on both sides of the section. Three to six repeated measurements of $\delta^{34} \mathrm{~S}$ were performed in four troilite inclusions (nos. 1-4) with a size of 300-400 $\mu \mathrm{m}$; other inclusions were analyzed without repetitions (Table 3 ).

As a whole, the $\delta^{34} \mathrm{~S}$ values are in the narrow range of $0.07-0.56 \%$. The average sulfur isotope composition of the Chelyabinsk meteorite is $0.31 \%$ in relation to VCDT and corresponds to the area typical of stone meteorites [10]. Individual troilite inclusions demonstrate the difference in the isotope composition, which exceeds the analytical error. For example, the difference between $\delta^{34} \mathrm{~S}$ values for inclusions nos. 1 and 2 is $0.27 \%$ and the maximal difference reaches $0.49 \%$ o (between inclusions nos. 13 and 16). Variations of the sulfur isotope composition of troilite from the Chelyabinsk meteorite most likely result from metamorphism of the parental body and/or shock transformations of the meteorite. However, reliable conclusions require further investigation of the isotope composition of the Chelyabinsk meteorite. 


\section{REFERENCES}

1. A. N. Krot, K. Keil, C. A. Goodrich, E. R. D. Scott, and M. K. Weisberg, in Treatise on geochemistry. Vol. 1. Meteorites, comets, and planets (Elsevier, Oxford, 2004), pp. 83-128.

2. R. N. Clayton, L. Grossman, and T. K. Mayeda, Science 182, 485 (1973).

3. R. N. Clayton, N. Onuma, and T. K. Mayeda, Earth Planet. Sci. Lett. 30, 10 (1976).

4. Society. Meteoritical, http://www.lpi.usra.edu/ meteor/metbull.php?code $=57165$ ).

5. Z. D. Sharp, Geochim. Cosmochim. Acta 54, 1353 (1990).
6. M. F. Miller, I. A. Franchi, A. S. Sexton, and C. T. Pillinger, Rapid Commun. Mass Spectrom. 13, 1211 (1999).

7. J. W. Valley, N. Kitchen, M. J. Kohn, C. R. Niendorf, and M. J. Spicizza, Geochim. cosmochim. acta 59, 5223 (1995).

8. R. N. Clayton and T. K. Mayeda, Earth Planet. Sci. Lett. 62, 1 (1983).

9. M. M. Grady, P. K. Swart, and C. T. Pillinger, Proc. Lunar Planet. Sci. Conf. 13, A289 (1982).

10. J. R. Hulston and H. G. Thode, J. Geophys. Res. 70, 3475 (1965).

Translated by A. Bobrov 